\title{
Pemetaan Kebutuhan Guru di Kecamatan Sungai Kakap Kabupaten Kubu Raya Berbasis Sistem Informasi Geografis (SIG)
}

\author{
Ryan Permana $^{\# 1}$, Chandra Lesmana ${ }^{\# 2}$ \\ "IKIP-PGRI Pontianak \\ Jalan Ampera No. 88 \\ ${ }^{1}$ ryanpermana.hidayategmail.com \\ ${ }^{2}$ chandralesmana87@gmail.com
}

\begin{abstract}
Abstrak- Penelitian ini bertujuan untuk: (1)menganalisis kebutuhan guru dijenjang SDN di Kecamatan Sungai Kakap Kabupaten Kubu Raya; dan (2)merancang pemetaan kebutuhan guru di Kecamatan Sungai Kakap Kabupaten Kubu Raya menggunakan Sistem Informasi Geografis (SIG). Metode dalam penelitian ini menggunakan analisis deskriptif. Analisis deskriptif dilakukan dengan cara mengumpulkan dan menyusun data yang diperoleh melalui observasi dan wawancara. Pengumpulan dan penyusunan data melalui observasi dan wawancara ini dilakukan dengan menggunakan teknik triangulasi. Dalam penelitian ini, triangulasi digunakan untuk mendapatkan keakuratan data menggunakan berbagai cara, prosedur, dan metode agar data yang diperoleh dapat dipercaya kebenarannya. Beberapa macam triangulasi yang digunakan dalam penelitian ini adalah: data triangulation dan situational triangulation. Hasil penelitian ini: (1)menunjukkan bahwa terdapat 1 sekolah yang membutuhkan 28 tenaga guru, diantaranya 1 kepala sekolah, 19 guru kelas, 3 guru penjaskes, 3 guru agama islam, 1 guru agama khatolik, dan 1 penjaga sekolah; dan (2)informasi pemetaan kebutuhan guru menggunakan aplikasi Arc View. Dalam aplikasi tersebut terdapat beberapa koordinat SDN yang memiliki informasi kebutuhuan, kekurangan, serta kelebihan guru dari seluruh SDN di Sungai Kakap Kabupaten Kubu Raya.
\end{abstract}

Kata Kunci-Guru, Pemetaan, Triangulasi

\section{Pendahuluan}

Pendidikan selalu menjadi pusat perhatian oleh banyak pihak. Upaya-upaya peningkatan kualitas pendidikan juga terus ditingkatkan agar pendidikan di Indonesia menjadi lebih baik. Salah satu unsur penting yang mempengaruhi kualitas pendidikan adalah tenaga pendidik. Tersebarnya tenaga pendidik diseluruh pelosok negeri menjadi salah satu fokus pemerintah dalam upaya meningkatkan kualitas pendidikan.

Tenaga pendidik di Kecamatan Sungai Kakap Kabupaten Kubu Raya memiliki pemetaan yang tidak merata. Kecamatan Sungai Kakap Kabupaten Kubu Raya merupakan daerah 3T (Tertinggal, Terdepan, dan Terluar) karena daerah ini terletak jauh dari ibu kota yaitu Kota Pontianak. Oleh karena itu, melalui Peraturan Bersama Menteri Negara Pendayagunaan Aparatur Negara dan Reformasi Birokrasi, Menteri Pendidikan Nasional, Menteri Dalam Negeri, Menteri Keuangan, dan Menteri Agama Nomor 05/X/PB/2011, SPB/03/M.PANRB/10/2011, 48 Tahun 2011, 158/PMK.01/2011,11 Tahun 2011 dibuatlah kebijakan tentang Penataan dan Pemerataan Guru Pegawai Negeri Sipil (PNS).

Kementerian Pendidikan dan Kebudayaan Direktorat Jenderal Pendidikan Dasar dan Menengah mengemukakan bahwa di Kecamatan Sungai Kakap Kabupaten Kubu Raya terdapat 69 Sekolah Negeri. Berikut data jumlah Sekolah Dasar Negeri (SDN), Sekolah Menengah Pertama Negeri (SMPN), dan Sekolah Menengah Atas Negeri (SMAN) sederajat di Kecamatan Sungai Kakap Kabupaten Kubu Raya.

TABEL I

DATA SEKOLAH

\begin{tabular}{|c|l|c|}
\hline No & \multicolumn{1}{|c|}{ Nama Sekolah Negeri } & $\begin{array}{c}\text { Jumlah } \\
\text { Sekolah }\end{array}$ \\
\hline 1 & Sekolah Dasar (SD) & 49 \\
\hline 2 & Sekolah Mengah Pertama (SMP) & 15 \\
\hline 3 & $\begin{array}{l}\text { Sekolah Menengah Atas (SMA) / } \\
\text { Sekolah Menengah Kejuruan (SMK) }\end{array}$ & 5 \\
\hline
\end{tabular}

(Sumber Data: Dinas Kabupaten Kubu Raya) 
Pemerataan guru PNS yang tidak merata merupakan tugas yang belum terlaksana secara maksimal oleh Dinas Kabupaten Kubu raya, karena lokasi sekolah yang mudah di jangkau memiliki rasio guru yang lebih banyak dibandingkan dengan sekolah yang sulit dijangkau. Sistem Informasi Geografis (SIG) dapat membantu UPT Pendidikan Kecamatan Sungai Kakap dalam pemetaan guru dengan referensi data spasial dan koordinat geografis. Dengan data spasial dan koordinat geografis, maka UPT Pendidikan Kecamatan Sungai Kakap dapat mengetahui sekolah-sekolah yang memiliki kekurangan guru. UPT Pendidikan Kecamatan Sungai Kakap akan merekomendasikan kepada Dinas Pendidikan Kabupaten Kubu Raya untuk memenuhi kebutuhan guru SDN, SMPN, dan SMAN/SMKN yang sedang membutuhkan tenaga guru.

Referensi [4] menyatakan bahwa SIG digunakan untuk menyimpan, memanipulasi, dan menampilkan informasi yang mengacu kepada data spasial. SIG digunakan untuk mendukung pengambilan keputusan dalam berbagai konteks pengelolaan lingkungan dan kesehatan di daerah kumuh di India.

Salah satu sistem informasi yang ditawarkan untuk menjawab permasalahan terkait kebutuhan guru di Kecamatan Sungai Kakap Kabupaten Kubu Raya adalah SIG. SIG merupakan suatu sistem informasi yang dirancang untuk bekerja dengan data yang bereferensi spasial atau berkoordinat geografis. Dengan penggunaan SIG, pendataan kebutuhan guru dapat dilihat bersama letak geografis suatu daerah di Kecamatan Sungai Kakap Kabupaten Kubu Raya.

1. Rumusan Masalah

Berdasarkan latar belakang tersebut maka dirumuskan masalah yaitu:

a. Bagaimanakan hasil analisis kebutuhan guru dijenjang Sekolah Dasar Negeri (SDN) di Kecamatan Sungai Kakap Kabupaten Kubu Raya?

b. Bagaimanakah pemetaan kebutuhan guru di Kecamatan Sungai Kakap Kabupaten Kubu Raya menggunakan Sistem Informasi Geografis (SIG)?

\section{Tujuan Penelitian}

Tujuan penelitian ini adalah:

a. Untuk menganalisis kebutuhan guru dijenjang Sekolah Dasar Negeri (SDN) di Kecamatan Sungai Kakap Kabupaten Kubu Raya.

b. Untuk memberikan pemetaan kebutuhan guru di Kecamatan Sungai Kakap Kabupaten Kubu Rayamenggunakan Sistem Informasi Geografis(SIG).

\section{TINJAUAN PUSTAKA}

a. Daerah 3T (Tertinggal, Terluar, Terdepan)

Daerah 3T (Tertinggal, Terluar, Terdepan) merupakan daerah yang kurang mendapatkan perhatian dari pemerintah. Kondisi pendidikan di daerah 3T masih kurang memadai dari segi sarana dan prasarana serta dari jumlah guru yang mengajar di sekolah tersebut, sebagaimana dalam [6]. Sedangkan menurut UndangUndang pasal 31 ayat 1 menjelaskan bahwa setiap warga negara berhak mendapatkan pendidikan yang layak guna mendapatkan ilmu pengetahuan yang baik.

Daerah kecamatan Sungai Kakap Kabupaten Kubu Raya merupakan daerah 3T. Sekolah Dasar Negeri (SDN), Sekolah Menengah Pertama Negeri (SMPN), dan Sekolah Menengah Atas Negeri (SMAN)/Sekolah Menengah Kejuruan Negeri (SMKN) di Kecamatan Sungai Kakap Kabupaten Kubu Raya memiliki rasio guru yang berbedabeda. Berikut data rasio guru di Kecamatan Sungai Kakap Kabupaten Kubu Raya.

\section{b. Peraturan Tentang Pemetaan}

Peraturan yang sesuai dengan pemetaan guru yaitu Peraturan Bersama Menteri Negara Pendayagunaan Aparatur Negara dan Reformasi Birokrasi, Menteri Pendidikan Nasional, Menteri Dalam Negeri, Menteri Keuangan, dan Menteri Agama Nomor 05/X/PB/2011, SPB/03/M.PAN-RB/10/2011, 48 Tahun 2011, 158/PMK.01/2011, 11 Tahun 2011tentang Penataan dan Pemerataan Guru Pegawai Negeri Sipil. Guru adalah pendidik profesional dengan tugas utama mendidik, mengajar, membimbing, mengarahkan, melatih, menilai, dan mengevaluasi peserta didik pada pendidikan anak usia dini jalur pendidikan formal, pendidikan dasar, dan pendidikan menengah.

\section{c. Pemetaan}

Pemetaan yaitu sebuah tahapan yang harus dilakukan dalam pembuatan peta. Langkah awal yang dilakukan dalam pembuatan data, dilanjutkan dengan pengolahan data, dan penyajian dalam bentuk peta. Pemetaan transisi diskursif dalam sains sekolah dari tingkat dasar sampai tingkat menengah, sebagaimana dalam [3], [8]. Dalam penelitian ini, buku teks sains sekolah dianggap sebagai sarana untuk mengatur wacana pedagogik masingmasing tingkat pendidikan yang digunakan dan sebagai cermin transisi pedagogik dalam pendidikan sains yang terjadi saat membentuk tingkat dasar ke tingkat menengah lebih rendah. Referensi [2] mengemukakan bahwa: terdapat 3 tahap proses pemetaan yang harus dilakukan yaitu: (1)Tahap Pengumpulan Data; (2)Tahap Penyajian Data; dan (3) Tahap Penggunaan Peta.

\section{d. Sistem Informasi Geografis}

Referensi [5] memungkinkan analisis data eksploratif dengan " zoom and pan " untuk menempatkan fitur fisik dalam konteks, " memfokuskan dan menyikat " untuk menyoroti subkategori data numerik (misalnya, saluran sensus kemiskinan tinggi), visualisasi dinamis, dan banyak gambar. Untuk mewakili perubahan dari waktu ke waktu, dan menghubungkan peta ke grafik, grafik, catatan lapangan, foto, atau audio. GIS adalah sistem informasi khusus yang menggunakan data spasial atau geografis yang dirujuk dan non-spasial atau atribut dan mencakup 
operasi yang mendukung analisis spasial, sebagaimana dalam [9].

Menurut pendapat para ahli maka Sistem Informasi Geografis (SIG) atau Geographic Information System (GIS) adalah suatu sistem informasi yang dirancang untuk bekerja dengan data yang bereferensi spasial atau berkoordinat geografi, atau dengan kata lain suatu SIG adalah suatu sistem basis data dengan kemampuan khusus untuk menangani data yang bereferensi keruangan/spasial bersamaan dengan seperangkat operasi kerja.

Gambar. 1 menunjukkan SIG memiliki komponenkomponen dalam sebuah sistem yaitu: orang (yang mengoperasikan sistem), aplikasi (prosedur yang digunakan untuk mengolah data), data (informasi yang dibutuhkan dan diolah dalam aplikasi), software (perangkat lunak GIS), dan hardware (perangkat keras yang dibutuhkan untuk menjalankan sistem).

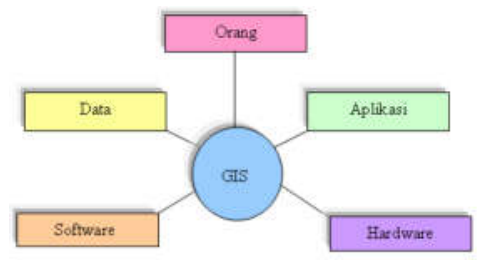

Gambar 1. Komponen SIG

\section{e. Kebutuhan Guru}

Kebutuhan guru merupakan refleksi terhadap tuntutan pemakai jasa profesional guru untuk memberikan pelayanan pendidikan terhadap peserta didik pada lembaga pendidikan pemakai guru yaitu sekolah, sebagaimana dalam [1]. Kebutuhan guru guna memberikan pelayanan pendidikan harus memenuhi persyaratan tertentu untuk menjamin bahwa pelayanan yang dituntut sesuai dengan harapan penggunanya. Persyaratan yang diharapkan sangat penting karena penyelenggaraan pendidikan menuntut keahlian profesional guru yang tidak semua orang dapat memilikinya. Referensi [1] juga menjelaskan bahwa konsep kebutuhan guru memiliki 2 konsep yaitu: demand and supply. Pada komponen demand, pertanyaan kunci yang relevan adalah:

1. guru untuk mata pelajaran apa atau bidang studi apa?

2. guru untuk jenis dan jenjang pendidikan yang mana?

3. strata, kualifikasi, atau kompetensi apa yang diperlukan?

4. tugas-tugas apa saja yang harus dilaksanakan?

Sedangkan pada komponen supply, pertanyaan kunci yang relevan diketengahkan antara lain berikut ini:

1. guru apa dan dengan kualifikasi tingkat mana yang perlu disiapkan?

2. apakah ketersediaan guru cukup tersedia?

3. berapa jumlah guru yang perlu disiapkan?

\section{METODE PENELITIAN}

a. Jenis Penelitian

Penelitian tentang "Pemetaan Kebutuhan Guru Di Kecamatan Sungai Kakap Kabupaten Kubu Raya Berbasis
Sistem Informasi Geografis (SIG)" menggunakan jenis penelitian kualitatif deskriptif. Penelitian kualitatif deskriptif ini digunakan untuk menganalisis kebutuhan guru SDN dikecamatan Sungai Kakap Kabupaten Kubu Raya.

b. Desain Penelitian

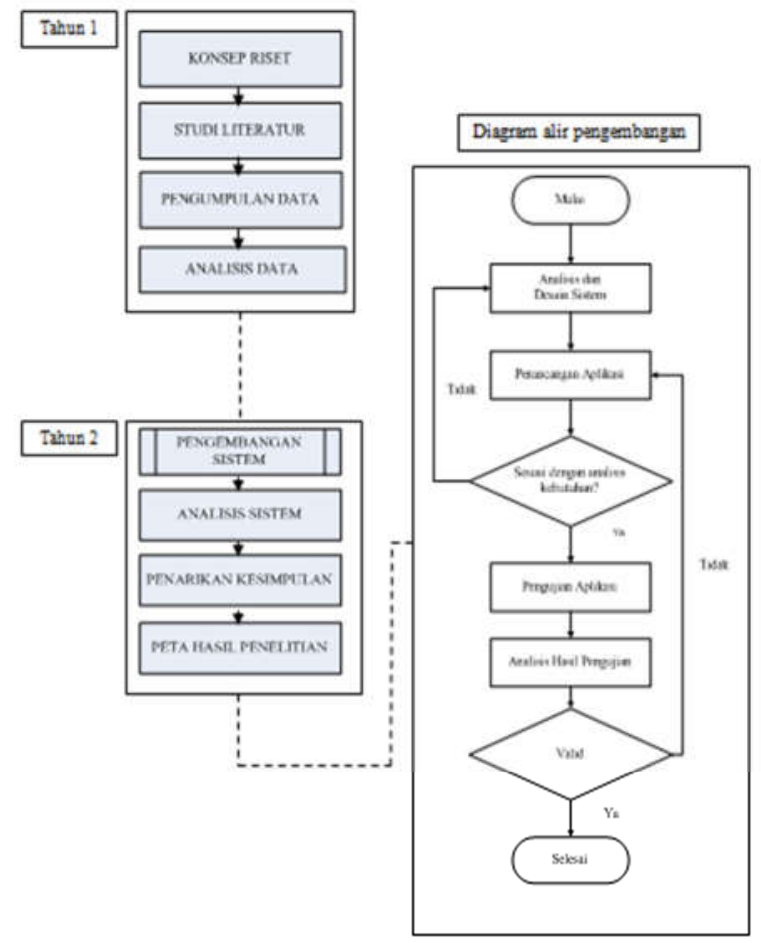

Gambar 2. Rancangan penelitian

Rancangan penelitian pada Gambar. 2 dapat dijelaskan sebagai berikut:

1. Studi Literatur

Studi literatur dilakukan guna memahami materimateri yang berkaitan dari beberapa literatur.

2. Pengumpulan Data

Pengumpulan data dari hasil observasi di Kecamatan Sungai Kakap Kabupaten Kubu Raya yang mencakup jumlah sekolah, jumlah ruang kelas, jumlah guru yang mengajar, dan jumlah siswa yang terbagi menjadi beberapa kategori seperti SDN dengan melakukan dokumentasi dan observasi.

3. Analisis Data

Analisis data dilakukan apabila peta untuk Kecamatan Sungai Kakap Kabupaten Kubu Raya. Serta melakukan analisis untuk kebutuhan guru mata pelajaran di Kecamatan Sungai Kakap Kabupaten Kubu Raya.

4. Pengembangan Sistem

Pengembangan sistem diawali dengan melakukan perancangan konseptual sistem yang dibangun, 
perancangan prototipe sistem, pengujian dan validasi sistem serta analisis hasil pengujian.

\section{Analisis Sistem}

Pada langkah ini, dilakukan analisis terhadap sistem secara keseluruhan untuk memudahkan dalam melakukan penarikan kesimpulan.

6. Penarikan Kesimpulan

Kesimpulan dirumuskan berdasarkan pengujian yang telah dilakukan apakah sistem yang dirancang mampu memberikan informasi tentang kebutuhan guru mata pelajaran di Kalimantan Barat yang ada berdasarkan klasifikasi analisis yang telah ditentukan.

c. Teknik Pengumpulan Data

Teknik pengumpulan Data yang digunakan dalam penelitian ini adalah teknik observasi dan teknik dokumentasi. Observasi adalah cara pengumpulan data dengan cara melakukan pencatatan secara cermat dan sistematik. Observasi harus dilakukan secara teliti dan sistematis untuk mendapatkan hasil yang bisa diandalkan, dan peneliti harus mempunyai latar belakang atau pengetahuan yang lebih luas tentang objek penelitian mempunyaidasar teori dan sikap objektif (Soeratno,1995: 99). Observasi yang dilakukan dapat direalisasikan dengan cara mengunjungi sekolah-sekolah dasar negeri yang terdapat di Kecamatan Sungai Kakap Kabupaten Kubu Raya. Dengan observasi, data lokasi SDN akan lebih akurat. Sedangkan teknik dokumentasi dilakukan dengan cara bekerja sama dengan UPT Kecamatan Sungai Kakap Kabupaten Kubu Raya untuk memeperoleh data kebutuhan guru SDN di Kecamatan Sungai Kakap Kabupaten Kubu Raya.

\section{d. Teknik Analisis Data}

Teknik analisis data dalam penelitian ini menggunakan analisis deskriptif. Analisis deskriptif dilakukan dengan mengumpulkan dan menyusun data yang diperoleh melalui observasi dan wawancara. Pengumpulan dan penyusunan data melalui observasi dan wawancara ini dilakukan dengan menggunakan teknik triangulasi. Referensi [10] menunjukkan triangulasi merupakan proses memastikan sesuatu dari berbagai sudut pandang. Dalam penelitian ini, triangulasi digunakan untuk mendapatkan keakuratan data menggunakan berbagai cara, prosedur, dan metode agar data yang diperoleh dapat dipercaya kebenarannya. Triangulasi yang digunakan dalam penelitian ini adalah data triangulation, sebagaimana dalam [10]. Data triangulation dilakukan untuk pengambilan data titik koordinat SDN di Kecamatan Sungai Kakap Kabupaten Kubu Raya. Dan kemudian titik koordinat tersebut akan dimasukkan kedalam data peta spasial. Data peta spasial dalam penelitian ini merupakan peta Kecamatan Sungai Kakap Kabupaten Kubu Raya.
IV. HASIL

Hasil penelitian ini merupakan pemetaan dengan mengunakan aplikasi Arc View. Dimana aplikasi ini menggambarkan secara spasial peta dari kecamatan sungai Kakap Kabupaten Kubu Raya. Data titik koordinat SDN dimasukkan kedalam peta spasial tersebut, sehingga peta Kecamatan Sungai Kakap Kabupaten Kubu Raya dilengkapi dengan titik-titik koordinat dari seluruh SDN yang terdapat di Sungai Kakap Kabupaten Kubu Raya.

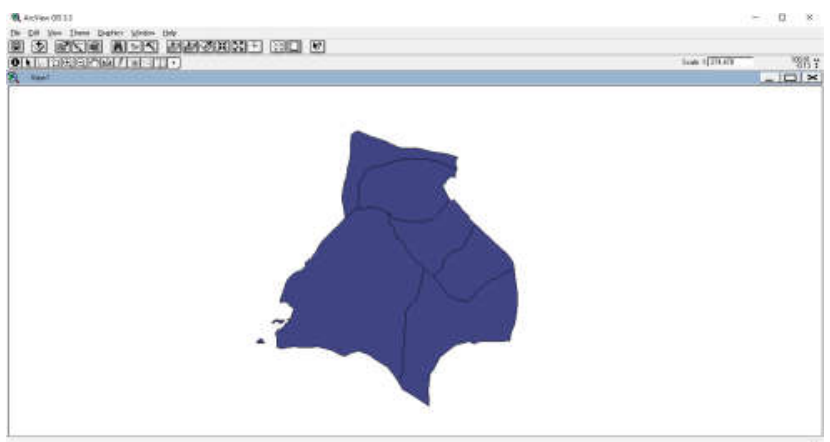

Gambar 3. Peta Kecamatan Sungai Kakap Kabupaten Kubu Raya

Gambar. 3 merupakan peta spasial dari Kecamatan Sungai Kakap Kabupaten Kubu Raya. Peta spasial tersebut digambar menggunakan polygon berdasarkan dari peta asli.

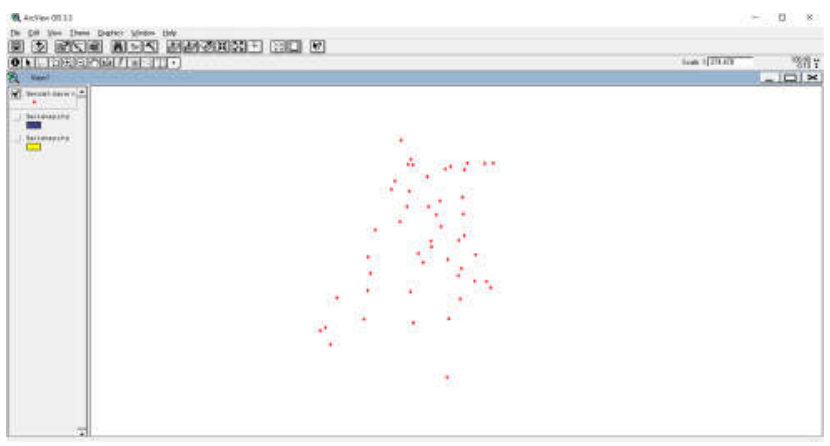

Gambar 4. Titik koordinat SDN

Gambar. 4 menunjukkan titik-titik koordinat SDN di Kecamatan Sungai Kakap Kabupaten Kubu Raya yang berjumlah 49 titik. 49 Titik tersebut mewakili dari 49 SDN di kecamatan Sungai Kakap Kabupaten Kubu Raya. Titik koordinat tersebut dikumpulkan dengan bantuan GPS (Global Positioning System) serta mengunjungi langsung SDN yang terdapat di Kecamatan Sungai Kakap. Dengan menggunakan GPS, titik koordinat sekolah akan tersimpan dan kemudian akan diolah kedalam bentuk data spasial. 


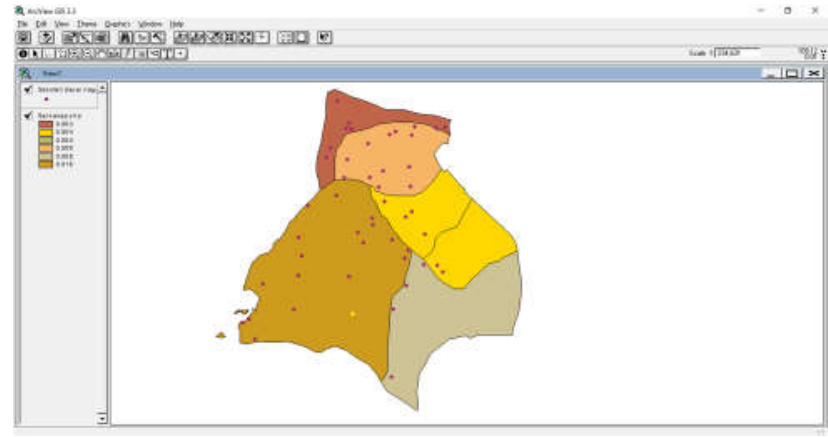

Gambar 5. Penggabungan peta dan koordinat

Gambar. 5 merupakan penggabungan peta dan 49 koordinat SDN di Kecamatan Sungai Kakap Kabupaten Kubu Raya digunakan untuk memberikan informasi sekolah-sekolah yang membutuhkan guru dijenjang SDN. Sehingga pemerataan guru di sekolah-sekolah dasar negeri dapat dilaksanakan.

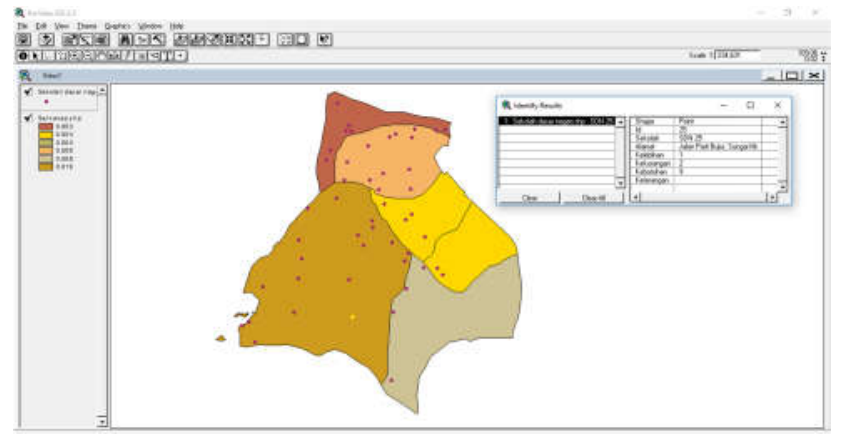

Gambar 6. Tampilan informasi tiap SDN

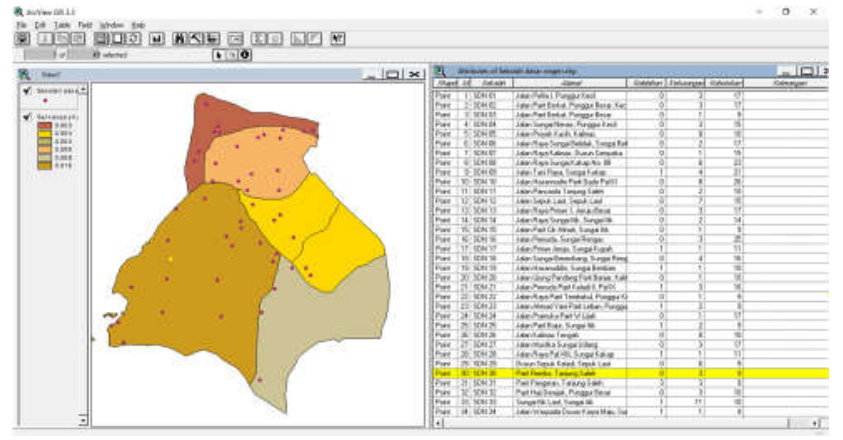

Gambar 7. Tampilan Informasi Seluruh SDN

Gambar. 6 merupakan informasi dari setiap SDN Kecamatan Sungai Kakap yang terdiri dari 49 titik koordinat dan 49 informasi. Sedangkan Gambar. 7 merupakan informasi dari keseluruhan SDN Kecamatan Sungai Kakap.

Berdasarkan hasil analisis bahwa SDN di Kecamatan Sungai Kakap Kabupaten Kubu Raya masih membutuhkan tenaga guru. Hasil analisis menunjukkan bahwa terdapat 1 sekolah yang membutuhkan 28 tenaga guru, diantaranya 1 kepala sekolah, 19 guru kelas, 3 guru penjaskes, 3 guru agama islam, 1 guru agama khatolik, dan 1 penjaga sekolah.

Dengan adanya pemetaan kebutuhan guru maka dapat membantu Dinas Pendidikan Kabupaten Kubu Raya untuk menginformasikan sekolah-sekolah yang lebih membutuhkan tenaga guru guna untuk pemerataan SDN yang terdapat di Kecamatan Sungai Kakap.

Perancangan aplikasi ini akan diuji dan divalidasi oleh ahli yaitu: karyawan UPT Puskom Sungai Kakap Kabupaten Kubu Raya. Berdasarkan hasil pengujian dan validasi, maka aplikasi ini dilanjutkan dengan tahap pengujian dengan menggunakan instrumen unjuk kerja. Hasil unjuk kerja menyatakan bahwa aplikasi ini memperoleh skor sebesar 75 dengan kategori "Baik dan siap digunakan". Dapat disimpulkan aplikasi ini dapat digunakan sebagai informasi kebutuhan guru SDN di Sungai Kakap Kabupaten Kubu Raya.

\section{KESIMPULAN}

Berdasarkan hasil analisis, kesimpulan dalam penelitian ini adalah:

1. Hasil analisis menunjukkan bahwa di Kecamatan Sungai Kakap Kabupaten Kubu Raya terdapat 49 SDN yang membutuhkan tenaga guru, diantaranya yaitu kepala sekolah, guru kelas, guru penjaskes, guru agama islam, dan guru agama khatolik.

2. Pemetaan yang dibuat menggunakan aplikasi Arc View. Dalam pemetaan tersebut dapat memberikan informasi kebutuhan guru kepada Dinas Pendidikan Kabupaten Kubu Raya. Sehingga pemerataan kebutuhan guru dapat dilaksanakan secara maksimal.

\section{UCAPAN TERIMA KASIH}

Peneliti mengucapkan terima kasih kepada:

1. KEMENRISTEKDIKTI sebagai atas bantuan dana pada skim Penelitian Dosen Pemula tahun 2018.

2. UPT Puskom Kecamatan Sungai Kakap Kabupaten Kubu Raya atas kerja sama dalam data Sekolah Dasar

3. JEPIN atas review jurnal pada penelitian ini.

\section{REFERENSI}

[1] Hartani. Manajemen Pendidikan. Yogyakarta. LaksBang PRESSindo. 2011.

[2] Intan. P. Aplikasi SIG Untuk Penyusunan Basisdata JaringanJalan Di Kota Magelang. Tugas Akhir Program Survey dan PemetaanWilayah Jurusan Geografi Fakultas Ilmu Sosial Universitas Negeri Semarang. 2007.

[3] Juhadi dan Dewi Liesnoor Setiyowati. Desain dan Komposisi PetaTematik. Semarang: Pusat Pengkajian dan Pelayanan Sistem Informasigeografis, Geografi UNNES. 2001

[4] Martin. J.B, Vasantha. K., and Joseph. R. "Using Geographic Information System (GIS) For Spatial Palnning and Enviromental Management in India: Critical Considerations". International Journal of Applied Science and Technology. Vol 2. 2012. Pp. 4054. 
[5] Nigel. F. \& Caesar. A. CAQDAS-GIS "Convergence: Toward a New Integrated Mixed Method Research Practice". Journal of Mixed Methods Research. Vol 3. No 4. 2009. pp 349-370.

[6] Sisca. F. Persepsi Mahasiswa Program Studi Kependidikan Universitas Pendidikan Indonesia Terhadap Program Pasca Sarjana Di Daerah Terdepan, Terluas, dan Tertinggal. Universitas Pendidikan Indonesia. 2013.

[7] Tim Penulis. Petunjuk Teknis Pelaksanaan Peraturan Bersama tentang Penataan dan Pemerataan Guru PNS. 2011.

[8] Vasilis. K\& Costas.D. "An Analysis of the Discursive Transitions across Different Modalities of the Pedagogic Discourse". Internation Journal of Learning. Vol 10. 2003. pp 3264-3274.

[9] Verka.J \& Angelina. N. The Use of GIS in Tourism Supply and WEB portal development. International Journal on Information Technology (IREIT), Vol. 20, No. 10. 2013.

[10] Basrowi \& Suwandi. (2008). Memahami Penelitian Kualitatif. Jakarta: Rineka Cipta 